ENTER2011

ENTER $11 \quad 18^{\text {th }}$ International Conference on Information

@ Innsbruck

Technology and Travel \& Tourism

January 26-28, 2011 - Innsbruck, Austria

\title{
The effects of online social media on tourism websites
}

\author{
Roberta Milano, \\ Rodolfo Baggio ${ }^{c}$, and \\ Robert Piattelli ${ }^{\mathrm{b}}$ \\ ${ }^{a}$ Master in Tourism Marketing and Web Marketing, \\ University of Genova - Savona Campus, \\ Savona, Italy \\ ${ }^{\mathrm{b}}$ BTO Educational, Florence, Italy \\ ${ }^{\mathrm{c}}$ Master in Economics and Tourism \\ Bocconi University, Milan, Italy \\ info@robertamilano.com \\ robert@btoeducational.it \\ rodolfo.baggio@unibocconi.it
}

\begin{abstract}
Web 2.0 and online social networking websites heavily affect today most of the online activities and their effect on tourism is obviously rather important. This paper aims at verifying the impact that online social networks (OSN) have on the popularity of tourism websites. Two OSNs have been considered: Facebook and Twitter. The pattern of visits to a sample of Italian tourism websites was analysed and the relationship between the total visits and those having the OSNs as referrals were measured. The analysis shows a clear correlation and confirms the starting hypothesis. Consequences and implications of these outcomes are discussed.
\end{abstract}

Keywords: Web 2.0, Travel 2.0, online social networks, tourism websites, Facebook, Twitter.

\section{Introduction}

At the close of the 20th century - roughly between 1997 and 2000 - a set of hardware and software technologies collectively known as the Internet had an enormous diffusion and radically changed most of our economic and social life. In the last few years a further "revolution" has impacted the way we communicate, work and conduct business. The buzzword for this is Web 2.0. 
Not really a technological advancement, since it relies on well developed and known tools, Web 2.0 rather identifies the changes occurred in the ways software developers and people make and use the Web. The applications that facilitate interactive information sharing, collaboration and formation of virtual communities form today a large part of cybernauts' daily activities and may be seen as a natural development of the original Berners-Lee's idea of "a collaborative medium, a place where we all [could] meet and read and write" (quoted in Richardson, 2006: 1).

Obviously, as it happened for the first Internet revolution, Web 2.0 could not remain unnoticed in activities genetically bound to the human species such as travel. The impact of Web 2.0 on tourism has been (and is) quite important as numerous publications, scholarly and not, continue to state.

Most of the analyses conducted so far assess the behaviour, the usage and the effects Travel 2.0 (the touristic version of Web 2.0) has as an important set of tools in the hands of a tourist and how it affects the image and the business of destinations, companies and organisations. Moreover, the adoption of such tools is considered to be quite important for improving the status of tourism websites. This generates the hypothesis that the role of OSNs in rising the number of visitors to referenced websites is significant.

Aim of this paper is to verify this impact. Two OSNs have been considered: Facebook and Twitter. The pattern of visits to a sample of Italian tourism websites has been analysed and the relationship between the total visits and those having the two OSNs as referrals have been measured.

The rest of this paper is organised as follows. Section 2 briefly surveys the role of Travel 2.0 and OSNs. Section 3 describes the methods used. Results and discussion are reported in sections 4 and 5. Some concluding remarks close the paper.

\section{Background}

The environment called Web 2.0 (or Travel 2.0) is today too well known to be further described here (would it be needed, the paper by Constantinides \& Fountain, 2008, is a good summary of the main issues on Web 2.0). A few considerations, however, are in order for better understanding the general framework in which this work has been conducted.

Tourism has long been the one of most important components of the online commerce world, whose impact has profoundly changed the structure of the industry. Online travel has anticipated ever since (and partly continues to do so) the development of new market dynamics and consumer behaviours. (Werthner \& Klein, 1999; Werthner \& Ricci, 2004).

With the introduction and the diffusion of the interactive Web 2.0 features and applications, tourism markets have become real conversations on one of the most thrilling subject for a human being. This happens in particular with OSNs which seem to have rapidly attracted a considerable attention by Internet users of all ages. They are, almost unanimously, recognised as the busiest environments, and this is valid especially for Facebook which has become in few years by way the largest (in number 
of users) and the most widespread (in geographical terms) online social network in the World (Fig. 1 after Cosenza, 2010).

As stated ten years ago by the Cluetrain Manifesto (Locke et al., 2000: xxiii): "people in networked markets have figured out that they get far better information and support from one another than from vendors." In the Web 2.0 era, the boundaries between information producers and users is blurred, and the usual concepts of authority and control are radically changed. Among the other consequences, marketing approaches aiming at improving online reputation are being greatly affected. Brand awareness, one of the objectives of classical marketing practices transforms into brand engagement, purpose of Marketing 2.0. This engagement is created by the perceptions, attitudes, and behaviours of those with whom the different companies and organisations are communicating. More importantly, especially for tourism, it passes necessarily through the experience (direct or indirect) a customer gains (Weinberger, 2007).

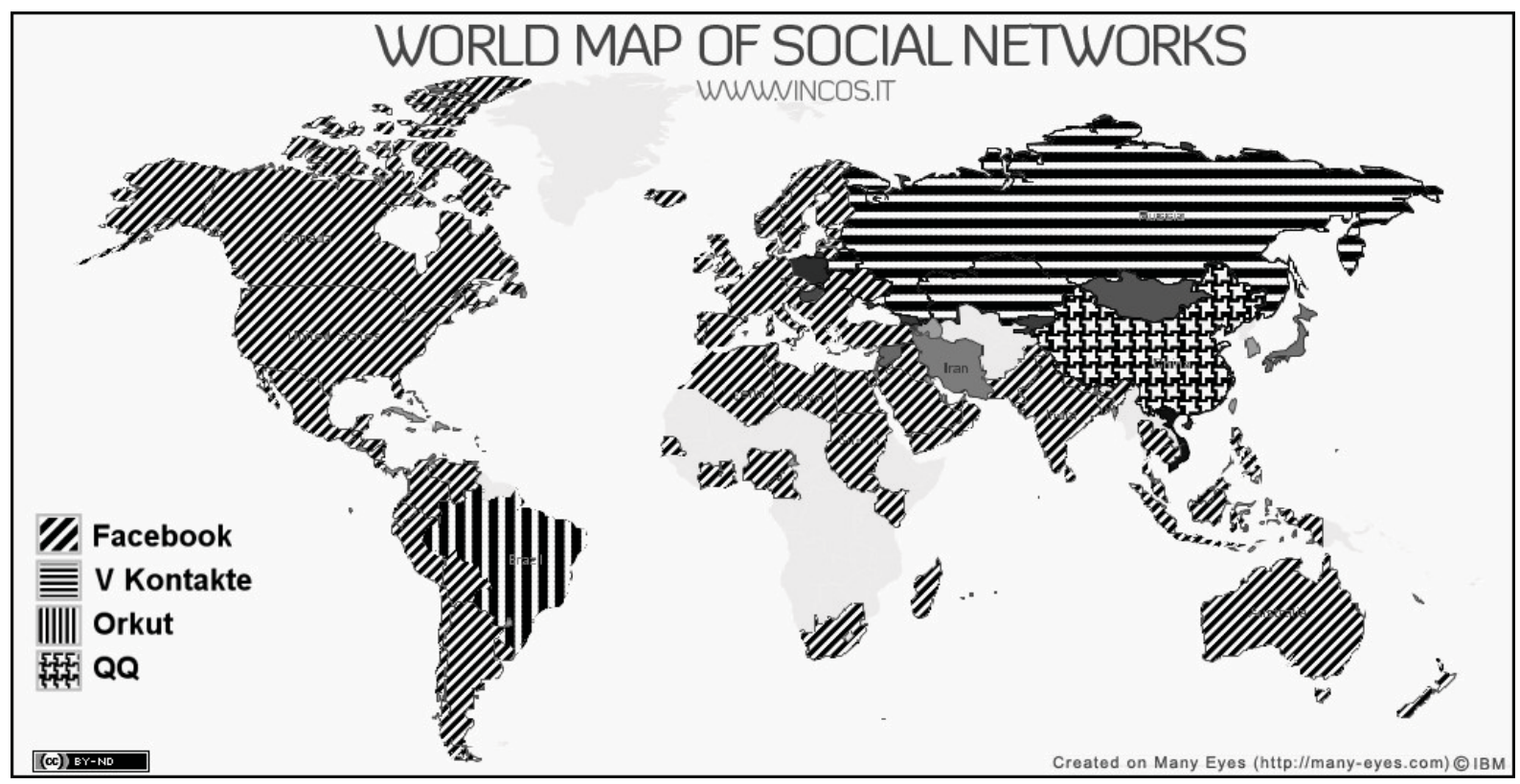

Fig. 1. The World Map of OSNs (adapted from Cosenza, 2010 for better black and white readability). Apart from a few areas (part of Latin America, Russia, China and some others), Facebook shows to be the most widespread OSN.

Contents generated by users (UGCs) have an acknowledged importance in all fields, and in tourism in particular (Akehurst, 2009). Their positive effects have recognised repercussions on quantifiable phenomena such as e-commerce, but also on intangible matters such as those related to the image or the informational side of specific products or services (termed sometimes info-commerce). Already in 2007, the annual Country Brand Index (CBI) measuring attractiveness of countries in several areas, stated that the Web had the highest importance $(67 \%)$ as channel to collect information about a tourism destination (CBI, 2007). On the other hand, the continuing growth of UGCs' influence, due to their wideness and deepness, makes them perceived as even more reliable than official sources for a tourist. According to PhoCusWright (2009) nine out of ten cybertravellers read (and trust) online reviews 
on tourism products and services (hotels, restaurants and destinations). Three phases are influential in this travel experience formation process (Milano, 2010):

- pre-experience, built on other people's travel stories, before travelling;

- $\quad$ experience during travel or stay, today increasingly shared real-time through mobile applications;

- post-experience, which disseminates comments, evaluations, emotions.

These issues form the foundations on which specialised Travel 2.0 tourism websites (TripAdvisor, WAYN, Tripwolf, Travelblog, Trivago etc.) have built their success. Today, however, we see a new phenomenon that can be interpreted as starting a new trend, especially in some countries: generic OSNs (Facebook first and Twitter) are being progressively more used in travel and tourism.

Italy is surely one of these countries, being at the first places in the World with regard to diffusion and usage of OSNs, Facebook in particular. According to Facebakers (http://www.facebakers.com/) there are (as per the month of August, 2010) almost 17 million Italian Facebook users, 56\% of the online population, which put Italy at the sixth place in country rankings. Italians seem to like much conversing and debating their travel experiences, tastes, perceptions and attitudes. Recent research reports travels as the second most discussed topic on Italian OSNs (Fabris, 2010), and a Google Insights for Search query shows an incredible growth of Facebook searches in Italy with respect to other technologically developed countries such as USA, UK, France or Germany (see Fig. 2).

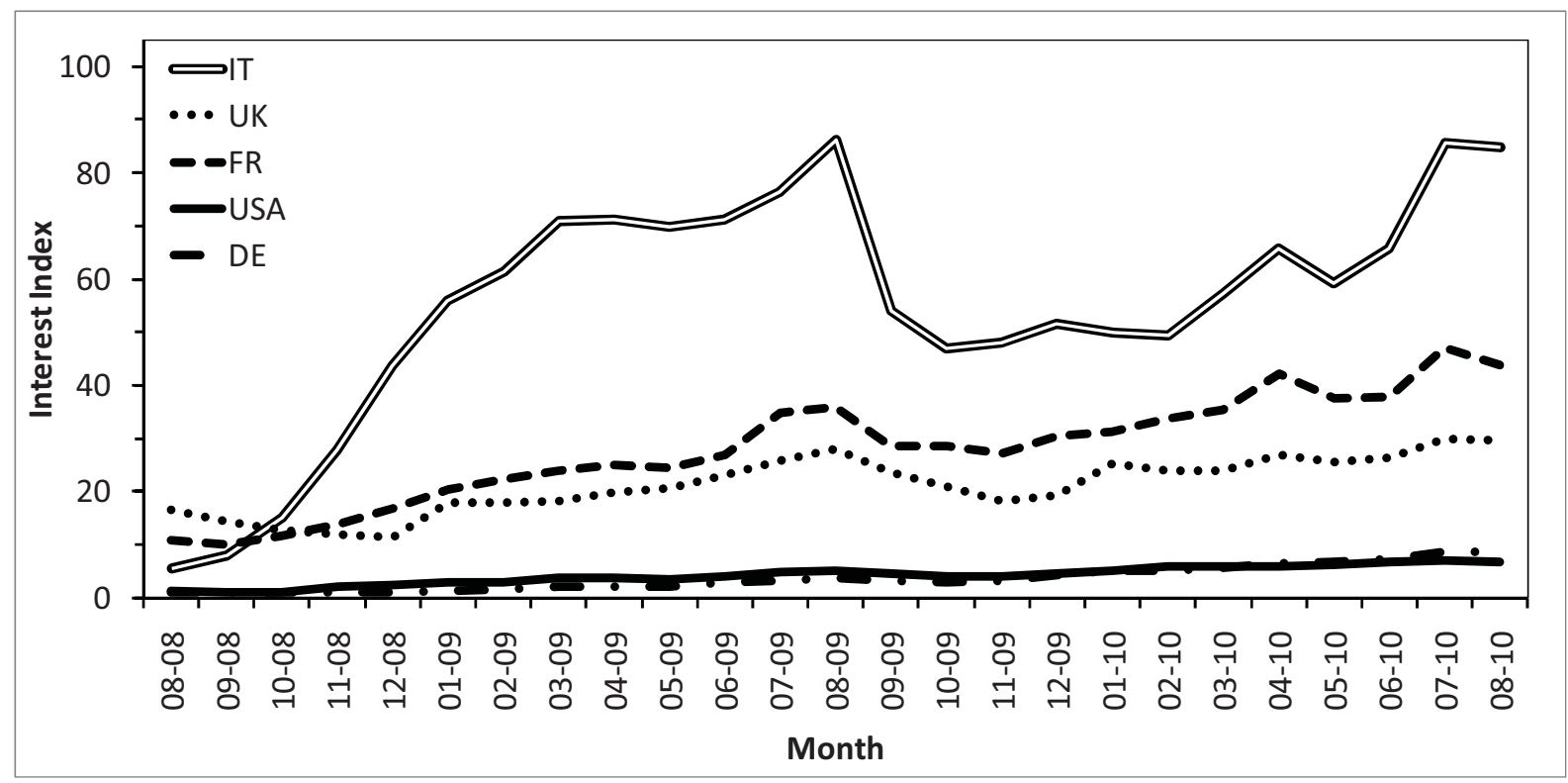

Fig. 2. Growth of interest in Facebook for travel in different countries (source: http://www.google.com/insights/search/\#cat=67\&geo=\&q=facebook\&cmpt=geo)

The phenomenon is a social convergence trend: specialised travel websites increase their sociality by adopting applications which enable real-time sharing of contents among the visitors, while giants such as Facebook try to occupy vertical markets through dedicated services or acquisitions of specialised companies as the social 
travel recommendation site Nextstop (see: http://www.insidefacebook.com/2010/07/ 08/facebook-acquires-social-travel-startup-nextstop/).

There are little doubts that the importance of Travel 2.0 features and tools, and specifically of social media environments, is growing fast. Many tourism businesses are, in one way or another, changing their approach to the manners of presenting themselves online (Au, 2010; Jones \& Yu, 2010; Schegg et al., 2008). However, most of the studies have assesses so far mainly the social and psychological effects, and have well confirmed the role played as sources of information and areas in which discussing various issues related to travels or stays (Chung \& Buhalis, 2008; Inversini \& Buhalis, 2009; Kasavana et al., 2010; Parra-Lopez et al., 2010; Schmallegger \& Carson, 2008; Xiang \& Gretzel, 2010). Some works have also discussed the effects of these tools on the image and the popularity of destinations or other tourism operators, mainly in the hospitality sector, in which the direct contact, real or virtual, with the customer and their crucial role for the good health of the companies (Burgess et al., 2009; Inversini et al., 2009; Matloka \& Buhalis, 2010; Sigala, 2010).

The general conclusion to-date in this field is that, beside the repeated statements on importance and role, tourism operators have not yet fully understood the new technological world by and still many concerns are brought forward. Credibility of the information online, possibility to forge for particular interests by unscrupulous competitors, privacy, overload of useless information, in addition to the usual (in the technology arena) lack of resources or skill shortage are the most reported issues (see all the literature cited so far).

These positions, however create a tension between demand (tourists, travellers, visitors) and supply (tourism businesses and organisations). As well reported by Xiang and Gretzel (2010: 186):

"social media Websites are "ubiquitous" in online travel information search in that they occur everywhere [...] no matter what search keywords a traveler uses. Certain social media Websites [...], which can be considered more comprehensive and travel-specific sites, are becoming increasingly popular and are likely to evolve into primary online travel information sources. [...]. The results confirm that tourism marketers can no longer ignore the role of social media in distributing travel-related information without risking to become irrelevant."

The rest of this paper gives further quantitative support to this stated importance of the role played by OSNs by directly assessing their effects and influence on tourism website visits. This is a topic which has not been discussed in the literature so far, but has an important value in trying to establish the real role of OSNs in supporting the efforts of tourism operators to attract visitors to their websites and influence their attitudes and memories.

\section{Materials and methods}

The data analysed in this work were provided by Shiny through their Shinystat service (http://www.shinystat.com/), an online platform specialised in Internet audience analysis and website statistics. The company is well known mainly in Italy, its 
country of origin and well diffused. More than 275,000 Italian websites use it. Cumulative data were collected concerning the visits to 19,902 websites in the categories: Travel and tourism and hospitality and restaurants. The timeframe spans a little more than two years (26 observations from August 2008 to August 2010 included). To all extent the sample can be considered quite significant, even if a single source of data was used. The data collected consisted of the series of total visits to Italian websites (TOT) and the contributions to these visits having Facebook (FB) and Twitter (TW) as referrals.

Shinystat uses a 30 minutes time window to define a visit; that is: all connections to a website coming from the same IP address in a $30 \mathrm{~min}$ period are considered as a single visit. This follows the proposals of the Web Analytics Association (WAA, 2008). Although not particularly meaningful per se, for the arbitrarity in the definition, when measured consistently over a period of time, visits are a good indicator of the behaviour of website with respect to its popularity (Dhyani et al., 2002; Polanco, 2003).

The global series (TOT) is an example of pooled (or cross-sectional) series (Sayrs, 1989): a series consisting of the linear composition of a number of different contributions. In order to assess the significance of these contributions to the global series a multiple linear regression can be used. This technique is well known and has been widely used in many other studies (Beck, 2008). In addition to the usual requirements of a regression analysis, the critical point in our case is to make sure that the independent variables do not suffer from multicollinearity (i.e. predictor variables are not highly correlated with each other) which may hinder the estimation of the effects of individual predictors.

The significance of the contributions due to FB and TW as referrals were assessed with a multiple regression where the time period is the dependent variable and the FB and TW contributions are the predictors. Tests for multicollinearity and normality of residuals were performed. The time series was also examined by using a standard simple decomposition method (Chatfield, 1996) to derive its main characteristics, seasonality in particular. All analyses have been carried out with SPSS version 17 (SPSS, 2008).

\section{Results}

The time series for total visits to Italian tourism websites (TOT) and the FB component are shown in Fig. 3. It must be noticed that, for space limitations, the figure uses two scale axes (the right one is for the visits from FB) in order to better show the series' behaviour (measurement scales differ of almost two orders of magnitude, for the same reason TW is omitted due to its very low values).

The maximum values for the contributions of $\mathrm{FB}$ and $\mathrm{TW}$ visits are recorded in the month of August 2010: $\mathrm{FB}=0.329 \%$; $\mathrm{TW}=0.002 \%$. When examining the series transformed into an index with the starting observation taken as base, TOT gets to 120 at the end of the period examined, while FB reaches 9438 and TW achieve 2280.The multiple regression uses the following model (Time is the time period number):

$$
\text { TOT }=\beta_{1} \text { Time }+\beta_{2} \text { FB }+\beta_{3} \text { TW }+ \text { Constant }+\varepsilon .
$$




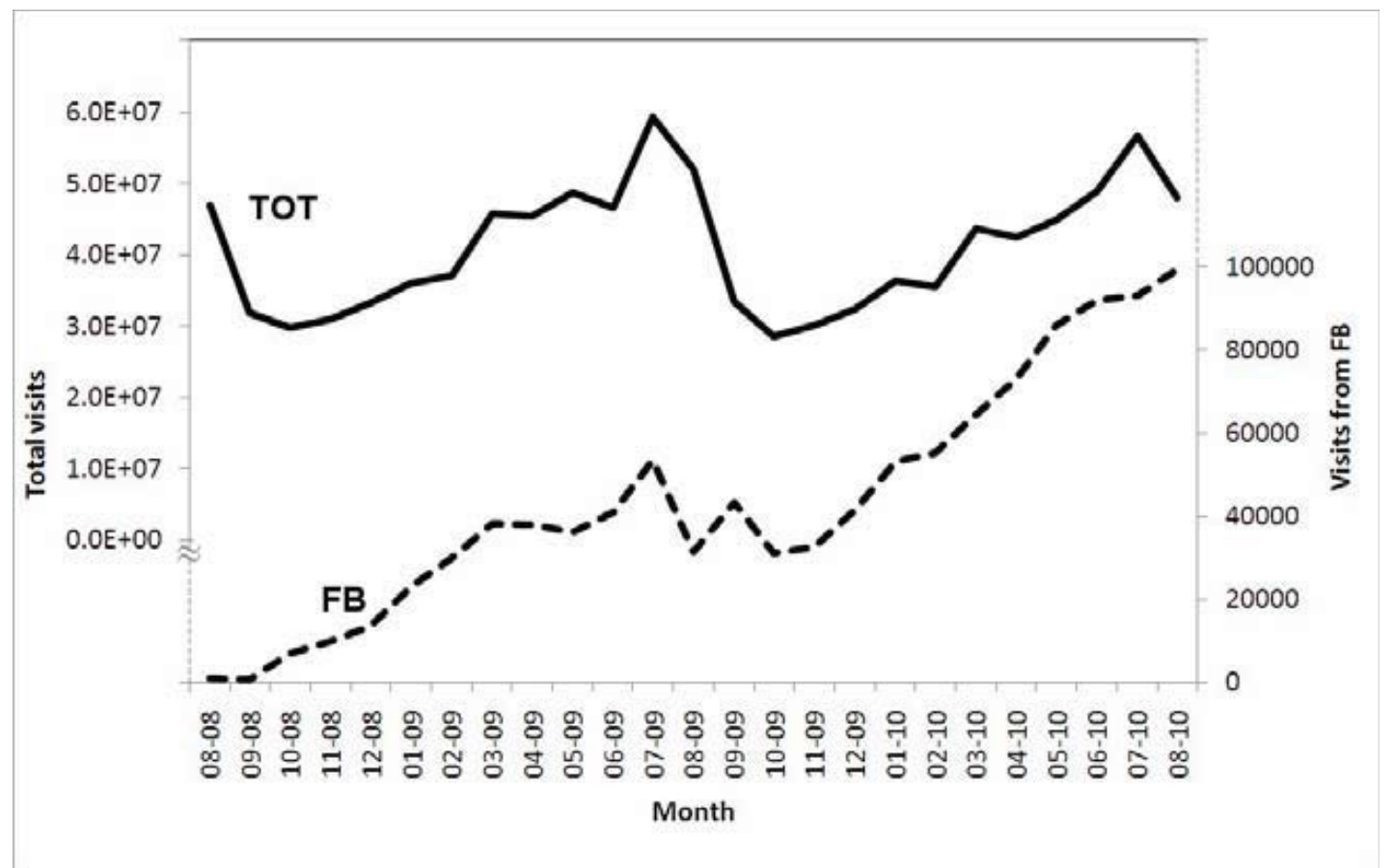

Fig. 3. Total visits to Italian tourism websites (TOT) and contribution to the visits from Facebook (FB). TW contributions are not reported for their very low values

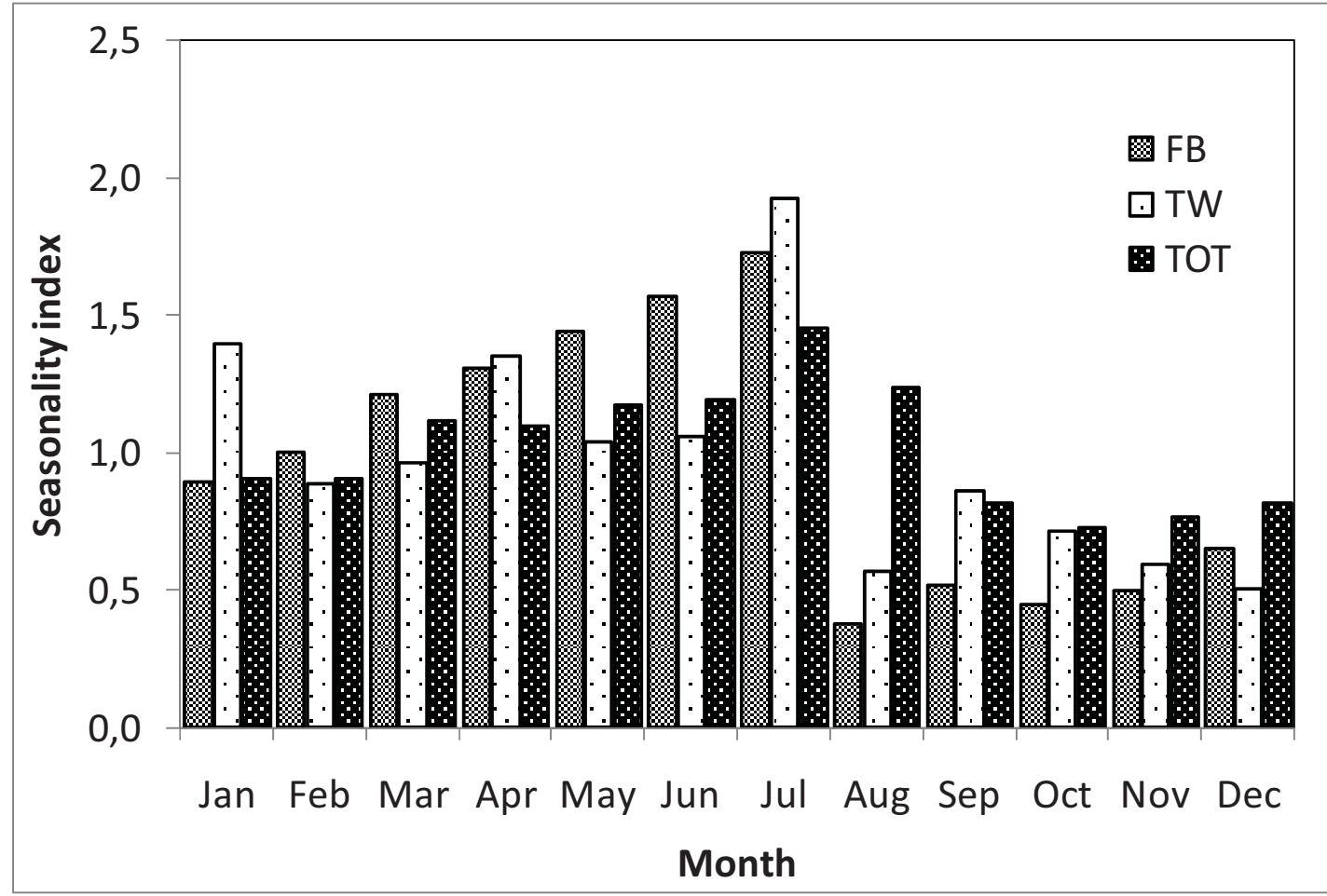

Fig. 4. Seasonality indices of the visits to websites for total visits (TOT) and Facebook (FB) and Twitter (TW) contributions

All the series show a marked seasonality (Fig. 4) with a peak in the summer months. This is typical of the Italian vacation patterns. 
Table 1. Results of the multiple regression analysis

\begin{tabular}{|c|c|c|c|c|c|}
\hline \multirow{2}{*}{ Predictor } & \multicolumn{2}{|c|}{ Coefficients } & \multirow{2}{*}{$\mathbf{t}$} & \multirow{2}{*}{ p-value } & \multirow{2}{*}{$\begin{array}{l}\text { Condition } \\
\text { Index }\end{array}$} \\
\hline & $\beta$ & Std. Error & & & \\
\hline (Constant) & $3.827 \mathrm{E} 7$ & $2.767 \mathrm{E} 6$ & 13.83 & .000 & 1.000 \\
\hline Time & $-1.868 \mathrm{E} 6$ & $5.947 \mathrm{E} 5$ & -3.14 & .005 & 4.143 \\
\hline FB & 538.2 & 129.7 & 4.15 & .000 & 8.155 \\
\hline TW & 11143.6 & 12044.1 & .93 & .365 & 15.809 \\
\hline
\end{tabular}

The results of the regression analysis are shown in Table 1. The predictor coefficients are reported along with their standard errors and statistical significance (indicated by a $t$ statistic and its associated p-value). The last column contains the condition index for which gauges the presence and the extent of multicollinearity (as known when it value is higher than 15 multicollinearity is a concern, when higher than 30 multicollinearity is a serious problem).

The coefficient of determination is $\mathrm{R}^{2}=0.523$ (adjusted $\mathrm{R}^{2}=0.455$ ) which can be considered providing a good fit. Residuals are normally distributed, a KolmogorovSmirnov (K-S) test produces $Z=0.833$ which has a (asymptotic) $p$-value $=0.492$ (the $\mathrm{K}-\mathrm{S}$ test has a null hypothesis of normality). The multicollinearity diagnostic does not show significant problems. The only slight effect found is for the TW component which has a condition index $=15.809$, indicating a limited problem which can be ignored (see Friendly \& Kwan, 2009).

\section{Discussion}

The results of the analysis lead to a number of interesting considerations. First of all the contribution of the two social media websites examined are of a low level. A higher proportion would have been expected, but this result is in agreement with other investigations, conducted on different bases, that show a limited usage of all Web 2.0 functionalities by tourism websites practically in every country (see for example Hamill et al., 2009; Schegg et al., 2008).

Little research has been conducted on this issue for what concerns Italy and, besides some popular press articles, no reliable data exist on how much OSNs are employed by the Italian tourism industry. In general, however, operators have seldom shown in the past highly favourable attitudes towards ICTs and, still today, make poor usage of them (Antonioli Corigliano \& Baggio, 2004; Minghetti \& Buhalis, 2010). Hence the advanced Web 2.0 features, OSNs in particular in this case, have a limited diffusion, at least at the present time.

Despite that, the growth of the FB and TW components is quite remarkable (some thousand times), mainly if we compare with the limited increase in total visits (a little more than one). This is an expected outcome and is in agreement with the many publications, scholarly and not, stating the quick growth in the usage of these virtual 
social environments. Also the seasonality effect is an expected result. The growth in usage in the first part of the year, peaking in July, is a clear indication of the role FB and TW play as important and reputed sources for travellers and tourists planning their summer travels, the most intense vacation period in Italy. This is in good agreement with other studies on the role of online social networks as information sources (Chung \& Buhalis, 2008; Inversini \& Buhalis, 2009; Xiang \& Gretzel, 2010).

The regression analysis shows the positive importance and the significance of the FB contributions to the total number of visits to a tourism website. It must be noted here that no information has been analysed in this work regarding the ownership of these Facebook resources (a study on this topic is ongoing). Very probably these contributions come from pages not directly connected with the websites, a further confirmation of the weight and the value of online social environments for the popularity and the success of tourist operators.

The usual disclaimers apply when it come to the limitations of this work. A single country has been considered, Italy, and a peculiar one for its very large proportion of Facebook-dependent online population. More studies will have the task of falsifying the outcomes presented here or adding further confirmations to the effects described.

The results presented here have an obvious importance for practitioners. From an academic point of view this work clarifies, for the first time, the role and the influence of OSNs on the popularity and traffic of tourism operators websites. In addition, it provides simple and effective methodological indications for gauging the significance of different contributions to a temporal phenomenon such as the one discussed here.

One final consideration is in order. The mere fact that there are many visits to a website does not necessarily imply a good image of the website owner. Many bad realisations exist and, for example, they are used sometimes to show how not to present an organisation online. In cases like these the websites may be visited by many. As already widely known, only good projects, well designed and carefully implemented, have a positive effect on the health of the actors presenting them online (Baggio, 2005; Bai et al., 2008; Jeong et al., 2003; Lee \& Kozar, 2006). This good consideration of the brand, then, produces a more favourable acceptance of the website which, in turn, reinforces the brand image, creating a virtuous cycle of appreciation (Perdue, 2002). Also, many studies argue that a solid, rich and appreciated website is a necessary foundation for the design of an effective and worthy online social media strategy (Constantinides \& Fountain, 2008; Miller et al., 2009; Murray, 2009). In this preliminary analysis these aspects have been neglected, the only aim has been to show the effects an OSN may have. Further investigations, already ongoing, will take care of these issues.

\section{Concluding remarks}

The main objective of this work was to show the effects of Web 2.0 features, and in particular of online social networks, on the popularity of tourism websites. The survey, conducted on data collected on a significant sample of Italian websites confirms this hypothesis. At the same time the outcomes also confirm the low presence of these features on the sites examined. 
Lack of resources, poor technical competence and sluggish management are usually claimed to explain the modest adoption of any type of information technology by tourism enterprises, for the most part very small. To these, in the case of social media, it would be possible to add also a certain level of suspicion, distrust and reluctance to share information, comments or suggestions with others.

However, the demonstrated (not only by this work) impact of modern ICTs and Web 2.0 poses a big challenge to any business or organisation (private or public) working in today's tourism arena. The tourist (traveller, visitor etc.) makes extensive use of these technologies and shows to appreciate quite much the possibilities offered by the Internet today. Difficult (if not impossible) to demonstrate scientifically, most of the declining performance of the Italian tourism in the last years might find a strong component in this poor employment of modern technologies.

Small and medium tourism enterprises are thus urged to rapidly move to a more favourable technological stance. Most, if not all, the adoption issues commonly quoted may find a solution in a firm increase in collaborative and cooperative attitudes which, as long shown, may overcome the weaknesses and deficiencies of single organisations.

\section{References}

Akehurst, G. (2009). User generated content: the use of blogs for tourism organisations and tourism consumers. Service Business, 3(1), 51-61.

Antonioli Corigliano, M., \& Baggio, R. (2004). Italian Tourism on the Internet - New Business Models. In K. Weiermair \& C. Mathies (Eds.), The Tourism and Leisure Industry Shaping the Future (pp. 301-316). New York: The Haworth Press.

Au, A. (2010). Adoption of Web 2.0 by Tourism Businesses in NSW (Research Reports). Sydney: Tourism New South Wales. Retrieved June, 2010, from http://corporate. tourism.nsw.gov.au/Sites/SiteID6/objLib40/Adoption-of-Web\%202Jan10.pdf.

Baggio, R. (2005). The relationship between virtual and real image of tourism operators. eReview of Tourism Research (eRTR), 3(5). Retrieved January, 2006, from http://ertr.tamu.edu/attachments/225_a-3-5-3.pdf.

Bai, B., Law, R., \& Wen, I. (2008). The impact of website quality on customer satisfaction and purchase intentions: Evidence from Chinese online visitors. International Journal of Hospitality Management, 27(3), 391-402.

Beck, N. (2008). Time-Series Cross-Section Methods. In J. Box-Steffensmeir, H. Brady \& D. Collier (Eds.), The Oxford Handbook of Political Methodology (pp. 475-493). Oxford: Oxford University Press.

Burgess, S., Sellitto, C., \& Karanasios, S. (Eds.). (2009). Effective Web Presence Solutions for Small Businesses: Strategies for Successful Implementation. Hershey, PA: IGI: Information Science Reference.

CBI. (2007). 2007 Country Brand Index. New York: FutureBrand. Retrieved January, 2010, from http://www.futurebrand.com.

Chatfield, C. (1996). The Analysis of Time Series (5th ed.). New York: Chapman \& Hall.

Chung, J. Y., \& Buhalis, D. (2008). Information Needs in Online Social Networks. Information Technology and Tourism, 10(4), 267-281.

Constantinides, E., \& Fountain, S. J. (2008). Web 2.0: Conceptual foundations and marketing issues. Journal of Direct, Data and Digital Marketing Practice, 9, 231-244.

Cosenza, V. (2010). World Map of Social Networks. Retrieved September, 2010, from http://www.vincos.it/world-map-of-social-networks/. 
Dhyani, D., Ng, W. K., \& Bhowmick, S. S. (2002). A Survey of Web Metrics. ACM Computing Surveys, 34(4), 469-503.

Fabris, M. (2010). ToscanaLab. Retrieved June, 2010, from http://www.slideshare.net/BTOEducational/gpf-monica-fabris-toscanalab-29-giugno2010

Friendly, M., \& Kwan, E. (2009). Where's Waldo? Visualizing Collinearity Diagnostics. The American Statistician, 63(1), 56-65.

Hamill, J., Attard, D., \& Stevenson, A. (2009). National destination marketing organisations and Web 2.0. Mercati e Competitività, 1, 71-94.

Inversini, A., \& Buhalis, D. (2009). Information Convergence in the Long Tail: The Case of Tourism Destination Information. In D. Buhalis, W. Höpken \& U. Gretzel (Eds.), Information and Communication Technologies in Tourism 2009 (pp. 381-392). Wien: Springer.

Inversini, A., Cantoni, L., \& Buhalis, D. (2009). Destinations' Information Competition and Web Reputation. Information Technology \& Tourism, 11(3), 221-234.

Jeong, M., Oh, H., \& Gregoire, M. (2003). Conceptualizing Web site quality and its consequences in the lodging industry. International Journal of Hospitality Management, 22(2), 161-175.

Jones, C., \& Yu, R. (2010). Travel industry uses Facebook and Twitter to reach customers. USA Today (7 July 2010). Retrieved July, 2010, from http://www.usatoday.com/tech/news/2010-09-07-travelsocialmedia07_CV_N.htm.

Kasavana, M. L., Nusair, K., \& Teodosic, K. (2010). Online social networking: redefining the human web. Journal of Hospitality and Tourism Technology, 1(1), 68-82.

Lee, Y., \& Kozar, K. A. (2006). Investigating the effect of website quality on e-business success: An analytic hierarchy process (AHP) approach. Decision Support Systems, 42(3), 1383-1401.

Locke, C., Levine, C., Searls, D., \& Weinberger, D. (2000). The Cluetrain Manifesto: The End of Business as Usual. Cambridge, MA: Perseus Publishings.

Matloka, J., \& Buhalis, D. (2010). Destination Marketing through User Personalised Content (UPC). In U. Gretzel, R. Law \& M. Fuchs (Eds.), Information and Communication Technologies in Tourism 2010 (pp. 519-530). Wien: Springer.

Milano, R. (2010). Cosa fare e cosa non fare nella Rete turistica. Il caso Italia.it. In G. Granieri \& G. Perri (Eds.), Linguaggi digitali per il turismo (pp. 47-48). Milano: Apogeo.

Miller, K. D., Fabian, F., \& Lin, S.-J. (2009). Strategies for online communities. Strategic Management Journal, 30(3), 305-322.

Minghetti, V., \& Buhalis, D. (2010). Digital Divide in Tourism. Journal of Travel Research, $49,267-281$.

Murray, R. (2009). A Good Example of a Bad Facebook Strategy. Retrieved March, 2010, from http://www.ploked.com/2009/05/29/a-good-example-of-a-bad-facebook-strategy/.

Parra-Lopez, E., Bulchand-Gidumal, J., Gutierrez-Tano, D., \& Diaz-Armas, R. (2010). Intentions to use social media in organizing and taking vacation trips. Computers in Human Behavior, (In Press: DOI: 10.1016/j.chb.2010.05.022).

Perdue, R. R. (2002). Internet Site Evaluations: The Influence of Behavioral Experience, Existing Images, and Selected Website Characteristics. Journal of Travel \& Tourism Marketing, 11(2), 21-38.

PhoCusWright. (2009). The PhoCusWright Consumer Technology Survey (2nd ed.). Sherman, CT: PhoCusWright.

Polanco, X. (2003). Concepts, Measures and Indicators in the Web Analysis. Paper presented at the Tercer Taller de Obtención de Indicadores de Producción Científica, Madrid, March 3-5.Retrieved June, 2010 from http://www.ricyt.org/interior/normalizacion/III_bib/ Polanco.pdf.

Richardson, W. (2006). Blogs, Wikis and Podcasts and Other Powerful Web Tools for Classrooms. Thousand Oaks, CA: Corwin Press.

Sayrs, L. W. (1989). Pooled time series analysis. Newbury Park, CA: Sage. 
Schegg, R., Liebrich, A., Scaglione, M., \& Ahmad, S. F. S. (2008). An Exploratory Field Study of Web 2.0 in Tourism. In P. O'Connor, W. Höpken \& U. Gretzel (Eds.), Information and Communication Technologies in Tourism 2008 (pp. 152-163). Wien: Springer.

Schmallegger, D., \& Carson, D. (2008). Blogs in tourism: Changing approaches to information exchange. Journal of Vacation Marketing, 14, 99-110.

Sigala, M. (2010). eCRM 2.0 applications and trends: The use and perceptions of Greek tourism firms of social networks and intelligence. Computers in Human Behavior, (In Press, DOI: 10.1016/j.chb.2010.03.007).

SPSS. (2008). SPSS (Statistical Package for the Social Sciences) (Version 17). Chicago, IL: SPSS Inc. (www.spss.com).

WAA. (2008). Web Analytics Definitions. Wakefield, MA: Web Analytics Association. Retrieved June, 2010, from http://www.webanalyticsassociation.org/resource/resmgr/ PDF_standards/WebAnalyticsDefinitions.pdf.

Weinberger, D. (2007). Everything Is Miscellaneous: The Power of the New Digital Disorder. New York, NY: Times Books.

Werthner, H., \& Klein, S. (1999). Information technology and tourism - a challenging relationship. Wien: Springer.

Werthner, H., \& Ricci, F. (2004). E-commerce and tourism. Communications of the ACM, 47(12), 101-105.

Xiang, Z., \& Gretzel, U. (2010). Role of social media in online travel information search. Tourism Management, 31(2), 179-188.

\section{Acknowledgements}

The authors wish to thank Shiny s.r.1. for making available data from their Shinystat system and Sonia Petrone for her useful suggestions. 